\title{
Temporal Changes in Tocochromanols in Leaves and Spikes of Barley Cultivars During the Development of the Caryopsis
}

\author{
Seturo SATO ${ }^{1}$, Toshiyuki KIMURA ${ }^{2,3 *}$ and Soichiro MORITA $^{1}$ \\ ${ }^{1}$ Forage Crop Research Division, NARO Institute of National Institute of Livestock and Grassland \\ Science (Nasushiobara, Tochigi 329-2793, Japan) \\ ${ }^{2}$ Environmentally Sound Agriculture Research Division, NARO Tohoku Agricultural Research Center \\ (Fukushima, Fukushima 960-2156, Japan)
}

\begin{abstract}
Temporal changes in tocochromanols during the development of caryopsis in two barley cultivars, 'Fiber-Snow' and 'Musashibo', were determined. Alpha-tocopherol (Toc) in leaves dominated among eight tocochromanol isomers in the leaves and spikes of both cultivars; suggesting that the tocochromanol content of the barley plant as a whole may be affected by the $\alpha$-Toc content in leaves. The pattern of temporal changes in leaf Toc content also differed between the cultivars. Leaf Toc content increased strikingly after anthesis in 'Fiber-Snow', whereas no conspicuous increase was observed in 'Musashibo'. Toc content was also significantly higher in 'Fiber-Snow' than in 'Musashibo' during the milky and dough stages. Tocotorienols (T3) were exclusively present in the spikes. They occurred around ten days after anthesis, peaking after the milky stage, whereas Toc had already accumulated at the first heading date. Alpha-T3 was the dominant form of the T3s, the accumulation of which preceded those of the $\beta$ - and $\gamma$-forms in both cultivars. Our findings revealed that the Toc content of the whole barley plant might remain high throughout caryopsis development, decreasing only toward the end and that $\mathrm{T} 3$ occurred after the mid-stage of the development. These results indicate that the current conventional harvest time for forage barley is appropriate, as farmers harvesting during caryopsis development will produce forage containing considerable tocochromanol.
\end{abstract}

Discipline: Agricultural chemicals / Crop production

Additional key words: forage, leaf, spike, tocopherol, tocotrienol

\section{Introduction}

Forage rice (Oryza sativa L.) is a promising forage resource in Japan and developing an annual crop rotation of forage rice and winter forage crops is thought to generate a higher crop rate and paddy field productivity in Japan. Forage rice is conventionally harvested in late fall, which is after the suitable seeding time of the Italian ryegrass (Lolium multiflorum L.), the most prevalent winter crop in Japan. Consequently, annual crop rotation combining forage rice with ryegrass is rare and there is a need to determine substitute crops for ryegrass to establish an annual crop rotation in paddy fields (Maeta et al. 2006). Winter small grain crops, including barley which has vigorous germination ability even under a low temperature in late fall, could be applicable as a late substitute. Over several years, the government has developed some agricultural projects to establish crop rotation systems combining forage rice with small grain crops, particularly barley.

One of the reasons why cattle farmers accept forage rice as feed is because of its high levels of $\alpha$-tocopherol ( $\alpha$ Toc), better known as one of the vitamin $\mathrm{E}$ forms and an antioxidant. The $\alpha$-Toc content of whole crop rice silages harvested at different mature stages was also previously demonstrated (Saigusa et al. 2006).

Tocopherols (Toc) and tocotrienols (T3) are collectively called tocochromanols and each has four isomers, labeled $\alpha$-, $\beta$-, $\gamma$ - and $\delta$-form. Of these eight tocochromanol forms, the main focus for livestock researchers and farmers has been $\alpha$-Toc because of its high antioxidant activity in beef cattle. Dietary $\alpha$-Toc supplementation is prevalent in the fattening of beef cattle, as it is known to retard color deterioration in displayed beef. Prior research has docu-

\footnotetext{
Present address:

${ }^{3}$ Crop Production Systems Division, NARO Agricultural Research Center (Tsukuba, Ibaraki 305-8666, Japan)

*Corresponding author: e-mail kmr@affrc.go.jp

Received 2 October 2013; accepted 8 july 2014.
} 
mented the effect of $\alpha$-Toc supplementation and discussed recommended amounts to prevent color deterioration in aged beef (Arnold et al. 1993, Nassu et al. 2011). In addition, feeding whole crop rice silage with high levels of $\alpha$ Toc material has also begun to attract researchers' attention. Yamada et al. (2012) reported the retardant effect of forage rice on the deterioration in beef color and showed how beef meto-myoglobin levels, the criterion of beef color deterioration, decreased when Japanese black beef cattle were fed fermented TMR (total mixed rations) containing whole crop rice silage.

For barley, the tocochromanols in the food grain have interested researchers. Falk et al. (2004) revealed the temporal and spatial accumulation of eight tocochromanol forms during the development of barley caryopsis and suggested their various functions in germ, pericarp and endosperm. Yamazaki et al. (1997) showed that virtually all tocochromanols were distributed around the seed coat and that T3 were more prevalent than Toc in the grain of malting barley.

Barley forage, meanwhile, comprises leaves, stems and immature spikes, since whole plants are harvested before they reach the yellow-ripe stage in barley forage production. However, the tocochromanol content of leaves and spikes during caryopsis development is not well known.

This study aims to improve understanding of the temporal changes in tocochromanol in leaves and spikes during the caryopsis development of two barley cultivars to determine the optimum harvesting time for maximizing the tocochromanol concentration.

\section{Materials and Methods}

\section{Plant materials}

Six-rowed (cv. Fiber-Snow) and two-rowed (cv. Musashibo) cultivars of barley were grown between November 2011 and May 2012 in the experimental field of the National Institute of Livestock and Grassland Science at Nasushiobara city, Tochigi prefecture in Japan. Although we had only a couple of commercial barley cultivars for forage, it was feasible to use them as forage crops because their fodder yields and quality were comparable to those of forage cultivars (Sato et al. 2014). The cultivar 'Fiber-Snow' is one of the feasible late-maturing cultivars, whereas 'Musashibo' is appropriate as a forage cultivar with heading date and maturing duration equivalent to those of 'FiberSnow' (Sato, unpublished). These two tested cultivars were selected to minimize the difference in the environmental effect on the tocotrienol accumulation tested. These cultivars were sown at a rate of $600 \mathrm{~g} / \mathrm{a}$ on 6 November, 2011, while the field was fertilized at a rate of 1.0-1.0-1.0 kg/a with a compound fertilizer before sowing. Plots were arranged in a randomized block design with three replica- tions; each plot size was $2.5 \times 5 \mathrm{~m}$. The first heading dates of barley plants were checked from 10 am to $2 \mathrm{pm}$ on the 2 nd and 3rd of the following May, while heading plants were tagged to identify the first heading date. The experiment defined the first heading date as the day when a spike tip emerged through a flag leaf. Ten or fifteen whole plants were sampled every two days at around 10 am and the spikes and upper two leaves (containing the flag leaves) were obtained from the whole plants to determine the tocochromanol content. Sampling began at the first heading date and was completed 42 days after the first heading. The samples were lyophilized at $-50^{\circ} \mathrm{C}$ under $-4.5 \mathrm{~Pa}$ for $30 \mathrm{~h}$, ground under room temperature and immediately stored at $30^{\circ} \mathrm{C}$ until analyzed.

\section{Tocochromanol determination}

Toc and T3 concentrations in leaves and spikes were determined by HPLC with fluorescence detection (FL) (Sookwong et al. 2007). Lyophilized samples (50 mg of powder) were homogenized in $3 \mathrm{~mL}$ of 2-propanol containing $0.025 \%(\mathrm{w} / \mathrm{v})$ butylated hydroxytoluene and the mixture was sonicated for $10 \mathrm{~min}$. Following mixing and centrifuging at 3,200 rpm for $10 \mathrm{~min}$, the supernatant was collected and filtered through a $0.45 \mu \mathrm{m}$ PTFE filter (Millipore, Bedford, MA, USA). Next, $200 \mu \mathrm{L}$ of the filtrate was diluted with $800 \mu \mathrm{L}$ of hexane and $20 \mu \mathrm{L}$ of this mixture was subjected to HPLC analysis. Separation was performed on a silica column (Inertsil SIL 100A-3, $4.6 \times 250 \mathrm{~mm}$, GL Science, Tokyo, Japan) at $40^{\circ} \mathrm{C}$. A mixture of hexane/1,4dioxane/2-propanol $(1000 / 40 / 5, \mathrm{v} / \mathrm{v} / \mathrm{v})$ was used as the mobile phase at a flow rate of $1.0 \mathrm{~mL} / \mathrm{min}$. T3 and Toc isomers were detected using a RF-10AXL FLD detector (excitation 294 nm, emission 326 nm; Shimadzu, Kyoto, Japan). Toc and T3 concentrations in samples were calculated using equations of calibration curves of standard T3 and Toc and data were subject to ANOVA to compare the tocochromanol content.

\section{Results}

Many plants in both cultivars reached their first heading on May 2 or 3, 2012. Caryopsis development was slower in 'Musashibo' than in 'Fiber-Snow'; full ripening occurred 40 days after first heading in 'Fiber-Snow', while 'Musashibo' did not reach full ripe stage before the end of the experiment (42 days after first heading date) (Table 1). Toc had already accumulated in both the leaves and spikes of both cultivars at the first heading date, whereas T3 was detected only in spikes and not until several days after anthesis. The days required for each maturing stage are shown in Table 1. 
Table 1. Days required to heading and anthesis dates and maturing stages from first heading date ${ }^{1}$

\begin{tabular}{lcccccc}
\hline \multirow{2}{*}{$\begin{array}{c}\text { cultivar } \\
\text { stage }\end{array}$} & $\begin{array}{c}\text { heading } \\
\text { date }\end{array}$ & $\begin{array}{c}\text { anthesis } \\
\text { date }\end{array}$ & $\begin{array}{c}\text { milky } \\
\text { stage }\end{array}$ & $\begin{array}{c}\text { dough } \\
\text { stage }\end{array}$ & $\begin{array}{c}\text { yellow ripe } \\
\text { stage }\end{array}$ & $\begin{array}{c}\text { full ripe } \\
\text { stage }\end{array}$ \\
\cline { 3 - 6 } Fiber-Snow & 2 & 8 & days after first heading & \\
Musashibo & 4 & 7 & 21 & 26 & 32 & 40 \\
\hline
\end{tabular}

${ }^{1}$ First heading date is May 2 or 3 in 2012.

${ }^{2}$ Cultivar 'Musashibo' did not reach full ripe stage before the end of the experiment.

Table 2. Tocopherol content of leaves and spikes of barley cultivars on heading and anthesis dates and in maturing stages ${ }^{1}$

\begin{tabular}{lccccc}
\hline \multirow{2}{*}{$\begin{array}{c}\text { cultivar } \\
\text { stage }\end{array}$} & $\begin{array}{c}\text { heading } \\
\text { date }\end{array}$ & $\begin{array}{c}\text { anthesis } \\
\text { date }\end{array}$ & $\begin{array}{c}\text { milky } \\
\text { stage }\end{array}$ & $\begin{array}{c}\text { dough } \\
\text { stage }\end{array}$ & $\begin{array}{c}\text { yellow ripe } \\
\text { stage }\end{array}$ \\
\cline { 3 - 5 } $\begin{array}{l}\text { leaves } \\
\text { Fiber-Snow }\end{array}$ & 11.3 & 13.0 & $20.2^{2}$ & 21.0 & 17.0 \\
Musashibo & 12.3 & $11.6^{2}$ & 12.7 & $8.5^{2}$ & 12.1 \\
\cline { 3 - 5 } probability & $\mathrm{NS}$ & $\mathrm{NS}$ & $*$ & $* *$ & $\mathrm{NS}$ \\
\hline spikes & & & & & \\
Fiber-Snow & 2.1 & 2.9 & $1.6^{2}$ & 1.8 & 0.9 \\
Musashibo & 0.5 & $0.6^{2}$ & 1.0 & $0.8^{2}$ & 1.4 \\
\hline probability & $*$ & $* *$ & $*$ & $*$ & $* *$ \\
\hline
\end{tabular}

${ }^{1}$ Refer to table labout days requiered to heading and anthesis dates and maturing stages.

${ }^{2}$ Data were obtained from the samples of following days because maturing dates shown in table 1 was one day before sampling days.

\section{Difference in tocochromanol (Toc) content between cultivars}

1) Toc: leaves showed no differences in Toc content on both the heading and anthesis dates, while during the milky and dough stages, Toc content in Fiber-Snow was twice that of 'Musashibo'. The content difference between the cultivars then decreased and there was no significant difference in the yellow-ripe stage (Table 2).

In the case of spikes, Toc levels were much lower than in the leaves in both cultivars at every investigative stage. Meanwhile, the Toc content in 'Fiber-Snow' spikes significantly exceeded that in 'Musashibo' from the heading date to the dough stage, although this was reversed in the yellowripe stage, when the content was higher in 'Musashibo' (Table 2).

2) T3: T3 was detected only in the spikes. There was no difference in T3 content between cultivars in the milky stage, several days after the beginning of T3 accumulation. However, the content in 'Musashibo' significantly exceeded that in 'Fiber-Snow' during the dough and yellow-ripe stages (Table 3).

In summary, significant differences in tocochromanol content were observed between cultivars, which were
Table 3. Tocotrienol content of spikes of barley cultivars in maturing stages ${ }^{1,2}$

\begin{tabular}{lccc}
\hline \multirow{2}{*}{ cultivar } & $\begin{array}{c}\text { milky } \\
\text { stage }\end{array}$ & $\begin{array}{c}\text { dough } \\
\text { stage }\end{array}$ & $\begin{array}{c}\text { yellow ripe } \\
\text { stage }\end{array}$ \\
\cline { 2 - 4 } Fiber-Snow & $1.2^{3}$ & 2.2 & 2.3 \\
Musashibo & 1.0 & $3.5^{3}$ & 3.3 \\
\hline probability & $\mathrm{NS}$ & $*$ & $*$ \\
\hline
\end{tabular}

${ }^{1}$ Tocotorienol exculusively presented in spikes after milky stage.

${ }^{2}$ Refer to table 1 about days required to each maturing stage.

${ }^{3}$ Refer to table 2 about sampling dates.

dependent on the maturing stage, tocochromanol type and organ.

\section{Temporal changes in tocochromanol forms}

A detailed analysis revealed temporal changes in the individual forms of tocochromanol during caryopsis development. 
1) Toc in leaves: Alpha-Toc dominated among the Toc in both cultivars and changes in Toc in the leaves resulted from that of the $\alpha$-form. The content of $\gamma$-form tended to increase slowly and levels were consistently low compared to levels of $\alpha$-form. Beta- and $\delta$-form content was negligible (Fig. $1)$.

The patterns of temporal changes in leaf Toc content differed between the cultivars. The Toc content of 'FiberSnow' increased five days after anthesis (12 days after the first heading date) and remained high until midway through the yellow-ripe stage, whereas no such conspicuous increase after anthesis was observed in 'Musashibo'. In the 'Musashibo' cultivar, only minor changes in Toc content were observed until the early yellow-ripe stage, followed by a transient decrease around the dough stage (Fig. 1).
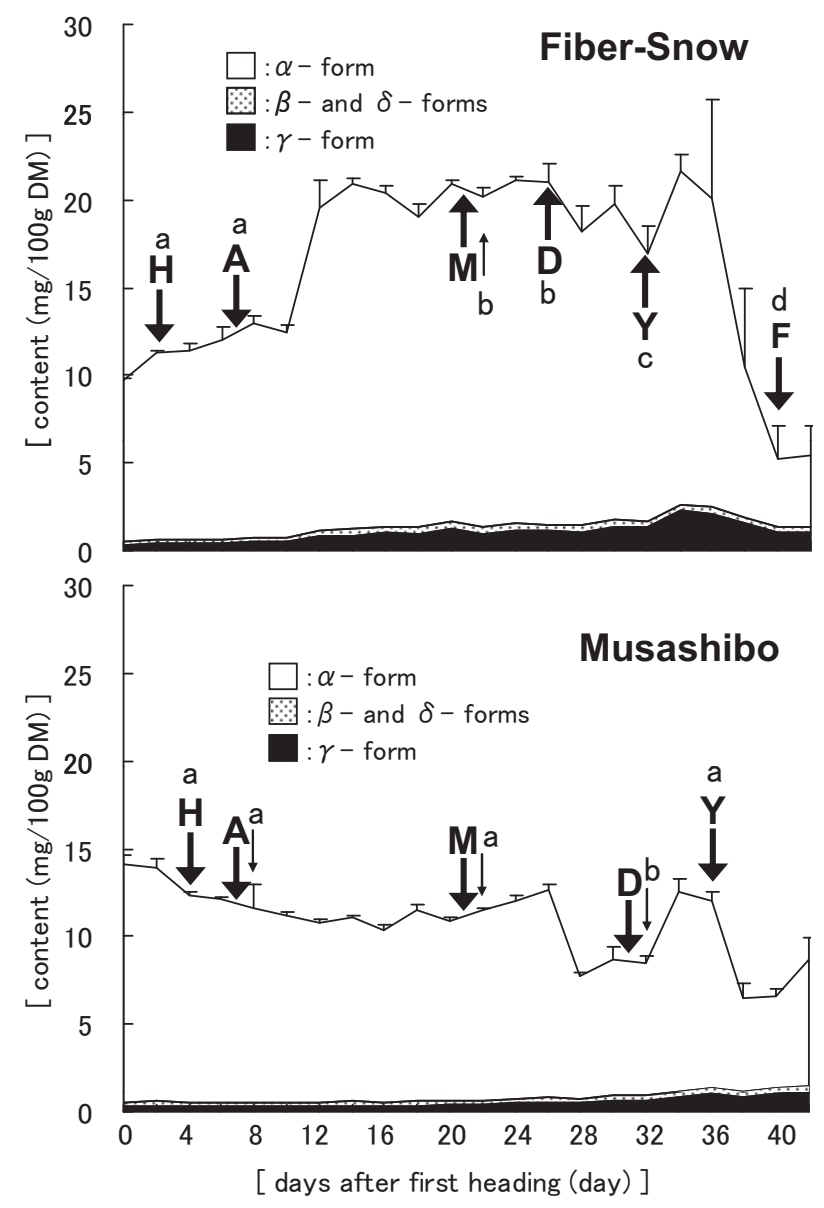

Fig. 1. Temporal changes of tocopherol forms in leaves of barley cultivars ${ }^{1,2,3}$

${ }^{1}$ Vertical bars represent standard errors of total tocopherol content.

${ }^{2}$ The capital letters follwed by gothic arrows show the begining of maturing stages and the letter $\mathrm{H}$, A, M, D, Y and F means headiing date, anthesis date, milky stage, dough stage, yellow ripe stage and full ripe stage, respectively.

${ }^{3}$ Same small letters followed by the arrows indicate no difference between content in maturing stages.
The striking increase in leaf Toc content after anthesis in 'Fiber-Snow' resulted in significantly higher levels in this cultivar than in 'Musashibo'; from anthesis through to the yellow-ripe stage. Overall, during caryopsis development, the Toc content of 'Fiber-Snow' exceeded that of 'Musashibo' (Table 2 and Fig. 1).

2) Toc in spikes: Overall, during caryopsis development, the Toc content of the spikes was much lower than that in the leaves of both cultivars. Toc presented as $\alpha$-, $\gamma$ - and $\delta$ forms; no $\beta$-form was detected in the spikes. The content of the $\alpha$-form fluctuated in the spikes, while the percentage content of $\delta$-form exceeded that in the leaves. However, $\alpha$ Toc was the dominant form during the caryopsis development in the spikes and generally affected temporal changes in Toc (Fig. 2).

The changing temporal pattern in Toc content in the spikes differed from that of the leaves in both cultivars. Toc content strikingly increased around anthesis in the spikes of both cultivars, whereas a conspicuous increase in the leaves was observed only in 'Fiber-Snow'. The Toc content in 'Fiber-Snow' exceeded that in 'Musashibo' except during the last 10 days or so of the experimental period, although the content fluctuated after the dough stage in both cultivars (Table 2 and Fig. 2).

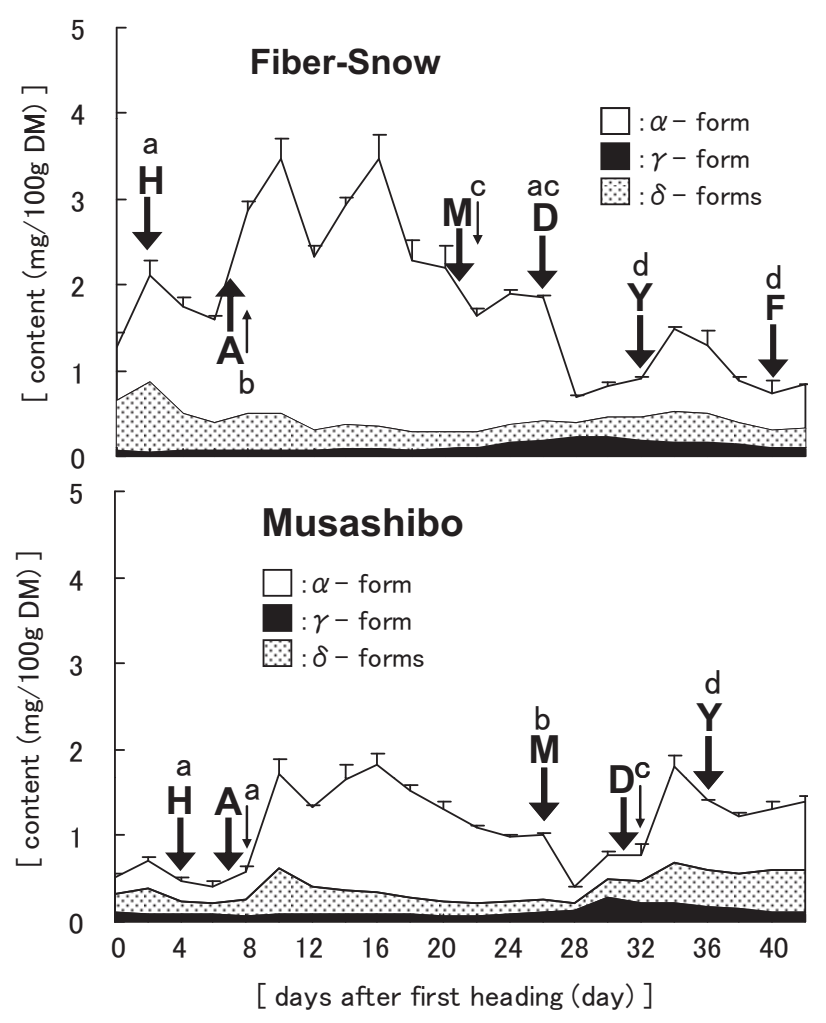

Fig. 2. Temporal changes of tocopherol forms in spikes of barley cultivars ${ }^{1,2}$

${ }^{1}$ Beta-form tocopherol was not detected.

${ }^{2}$ Refer to figure 1 about vertical bars and capital and small letters followed by arrows. 


\section{3) $\mathrm{T3}$ in spikes}

The temporal change in the content of the individual T3 form is shown in Figure 3. T3 were detectable exclusively in the spikes and presented as $\alpha-, \beta$ - and $\gamma$ - forms. T3 started to accumulate after anthesis in both cultivars, in contrast to Toc, which had accumulated by the first heading date (Figs. 2 and 3). The occurrence of $\alpha$-T3, the dominant form, preceded those of $\beta$ - and $\gamma$ - forms. Later on, T3 content increased steadily in 'Fiber-Snow' and sharply in 'Musashibo', while the content after the dough stage remained higher than in the milky stage in both cultivars (Fig. 3).

\section{Discussion}

Tocochromanols, better known as vitamin E, have antioxidative properties. Supplementation with $\alpha$-Toc, which has the highest antioxidant activity among the four Toc isomers, is prevalent in the fattening of beef cattle, as it has been shown to retard color deterioration in displayed beef. The current experiment revealed temporal changes in the tocochromanol content of leaves and spikes in two barley cultivars intended for forage use during caryopsis development.

Our findings indicate that $\alpha$-Toc content is higher in leaves than the other tocochromanols isomers throughout spikes and the upper two leaves. This suggests that the tocochromanol content of the whole barley plant is affected by the $\alpha$-Toc content in the upper two leaves, although there is a need to investigate the effect of senescent leaves on Toc content in the whole plant, since whole plants, including lower senescent leaves, are harvested in forage production. In a wheat plant (Triticum aestivum L.), the dry weight of the upper two leaves did not decrease after the heading date, whereas that of all but a few lower remnant leaves steadily decreased and the lowest leaves died off the plant at the late stage of caryopsis development (Tsuyuzaki \& Kawashima 1993). In this experiment, even in the younger upper two leaves, $\alpha$-Toc content decreased strikingly during the yellow-ripe stage in both cultivars (Fig. 1), suggesting that the $\alpha$-Toc content of lower leaves might begin to decrease earlier than the yellow-ripe stage. These findings suggest that the tocochromanol content of the barley plant could be affected by the $\alpha$-Toc content in the upper two leaves.

It is generally thought that tocopherol is produced in chloroplasts, which are far more numerous in leaves than stems. Because the tocopherol content in stems is much lower than that in leaves, we did not measure the tocochromanol content in the stems of these two cultivars, although we did detect tocopherol in the stems of the food rice cultivar 'Akitakomachi'. Although the content in the stems was comparatively low, it was not negligible (Kimura, unpublished). Further experiments are necessary to clarify the

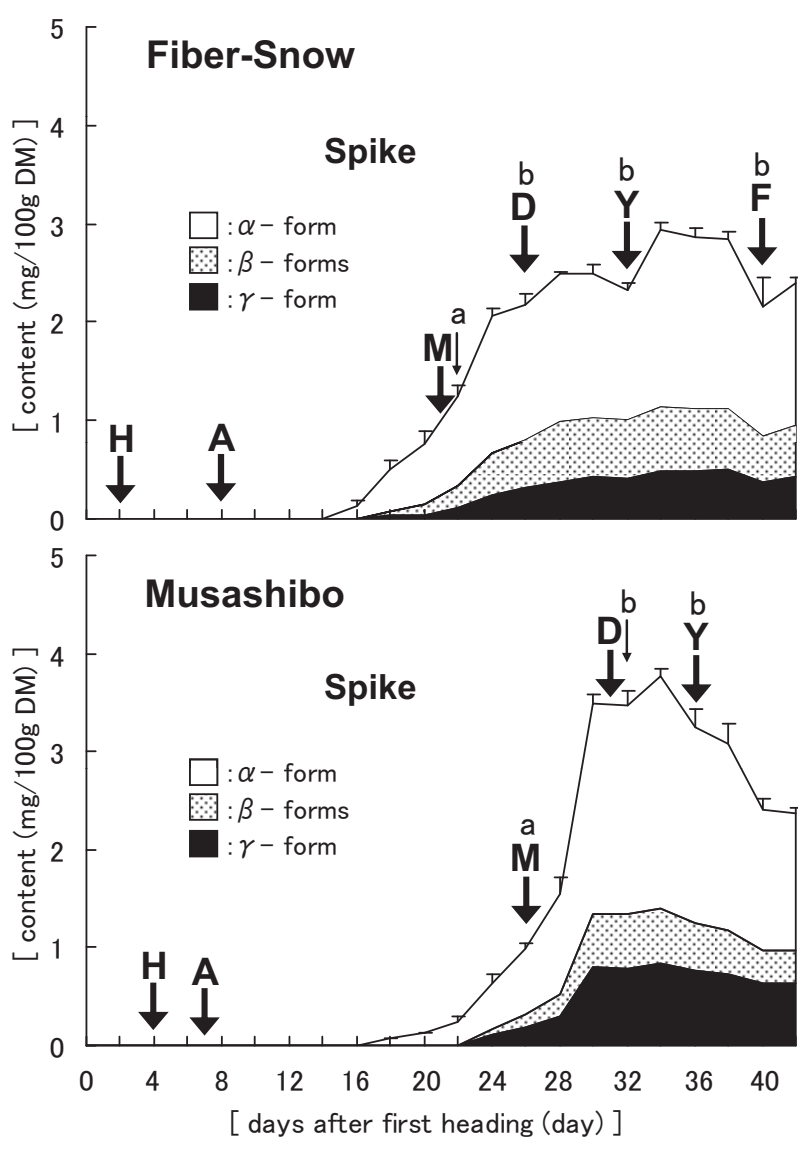

Fig. 3. Temporal changes of tocotorienol forms in spikes of barley cultivars ${ }^{1,2}$

${ }^{1}$ Tocotrienols were exclusively detected in spikes and $\delta$ - form were not detected.

${ }^{2}$ Refer to figure 1 about vertical bars and capital and small letters followed by arrows.

tocochromanol content of whole plants; including measurement of the content in stems.

Considerable Toc had already accumulated in the leaves of both cultivars at the beginning of caryopsis development and remained steady or increased up to the yellowripe stage (Fig. 1). The initial step of Toc biosynthesis in the chloroplast involves phytyl pyrophosphate (PPP) condensing with homogentisate (HGA), catalyzed by HGA phytltransferase (HPT); PPP and HGA are precursors of the phytol and chromane rings, respectively. In addition, a senescent leaf has another Toc biosynthesis process, in which separated phytol from chlorophyll through chlorophyll degradation is condensed with a chromane ring (Sabater \& Rodriguez 1978, Rise et al. 1988, Piesker et al. 1989). Reports that a decrease in chlorophyll content is associated with an increase in $\alpha$-Toc support this theory (Rise et al. 1988, Piesker et al. 1989). The duration of the relationship between Toc content and chlorophyll content (leaf senescence) depends on the senescence treatment and species. Piesker et al. (1989) reported that $\alpha$-Toc content in 
detached leaves of meadow fescue (Festuca elatior L.) decreased six days after senescence treatment in an incubator, although it had increased three days after such treatment. Matsuzaka et al. (2013) demonstrated that tocopherol in rice flag leaves (cv. Koshihikari) occurred or increased during the mid-stage of development (26 days after anthesis) and that high levels of Toc continued to the end of the experiment (50 days after anthesis). In the barley cultivars investigated to date, it is possible that Toc might accumulate more rapidly than in rice. The pattern of temporal change in Toc content in leaves differed for the barley in our experiment than for rice in prior reports (Matsuzaka 2013), although no reasons for this difference have yet been ascertained.

Meanwhile, the temporal pattern of changes in $\alpha$-Toc in the leaves differed between cultivars. In the case of 'Fiber-Snow', $\alpha$-Toc content increased strikingly in the leaves a couple of days after anthesis, almost doubling during that period, although no such conspicuous increase was observed in 'Musashibo'. The high content in 'Fiber-Snow' then remained unchanged until midway through the yellowripe stage. The difference in Toc content between cultivars at the optimum harvesting time - i.e. the milky and dough stages - resulted from the conspicuous increase in $\alpha$-Toc content in the leaves of 'Fiber-Snow'. Altogether, the Toc content in the leaves was higher in 'Fiber-Snow' than in 'Musashibo' (Table 2 and Fig. 1). Although researchers have reported the difference in Toc content in kernels during caryopsis development (Folk et al. 2004), few have considered the content in leaves. When detached leaves of barley and oats (Avena sativa L.) were incubated for senescence treatment, chloropyllase activity and chlorophyll degradation differed between species during senescence (Sabater \& Rodorigues 1978). Further research that reveals the cultivar characteristics in terms of chlorophyll degradation might explain the cultivar difference in tocochromanol accumulation patterns, since chlorophyll degradation through the hydrolytic enzyme during senescence is considered the first step of Toc biological synthesis.

T3 was exclusively found in the spikes of both cultivars. In the spikes, T3 occurred several days after anthesis, in contrast to Toc, which had already accumulated at the beginning of heading (Figs. 2 and 3). This Toc was concentrated in the uppermost part of the central axes, rachillas and glumes other than the caryopses. Falk et al. (2004) reported that T3 occurred in the caryopsis of two tested barley cultivars at the first sampling date, ten days after anthesis. Our result for the first occurrence of T3 agreed with theirs. These results indicate that $\mathrm{T} 3$ accumulation occurs several days after anthesis in barley. Although T3 exclusively accumulated in the spikes and the content was comparatively low, the antioxidant activity of T3 reportedly far exceeded that of Toc (Serbinova et al. 1991), so that a lower content of T3 in barley plants would not necessarily mean less biological activity in barley forage. Further research is needed to evaluate the content of individual tocochromanol isomers in both leaves and spikes, as well as their biological activity in barley cultivars.

With the relatively new perspective of tocochromanol utilization, suitable harvest times for forage barley could vary quite widely in our experiment, since the cultivars investigated have been shown to contain high levels of $\alpha$ Toc throughout caryopsis development until just before the end of development. We found that $\mathrm{T} 3$ began to occur in the mid-stages of development and peaked at the late stages. Cattle farmers in Japan conventionally harvest forage barley from milky to early yellow-ripe stages to avoid lodging and produce highly nutritive and fermented ensilage. Our results indicate that conventional harvest schedules for forage barley might be appropriate, since they are likely to produce barley forage with high tocochromanol content.

To minimize the environmental effect on tocochromanol accumulation, we tested cultivars with similar heading dates and maturing duration. Even so, the accumulation patterns of the tested cultivars clearly differed. We could not conclude whether the difference in accumulation patterns depended on the spike morphology of two-rowed versus six-rowed cultivars. In addition, our results were obtained from an experiment involving a single season, meaning further research is necessary to clarify changes in the temporal pattern of tocochlomanols in barley in greater detail.

\section{References}

Arnold, R.N. et al. (1993) Tissue equilibration and subcellular distribution of vitamin $\mathrm{E}$ relative to myoglobin and lipid oxidation in displayed beef. J. Anim. Sci., 71, 105-118.

Falk, J. et al. (2004) Tocopherol and tocotrienol accumulation during development of caryopses from barley (Hordium vulgare L.) Phytochemistry, 65, 2977-2985.

Maeta, A. et al. (2006) Establishment of the double-cropping system of the forage rice and forage wheat in a paddy field. Tochigiken Rakunou Shikenjo Kenkyu Houkoku (Bulletin of the Tochigi Prefectural Dairy Farming Experiment Station), 129, 29-37 [In Japanese with English summary].

Matsuzaka, K. et al, (2013) Investigation of tocotrienol biosynthesis in rice (Oryza sativa L.) Food Chemistry, 140, 91-98.

Nassu, R. T. et al. (2011) Effect of $\alpha$-tocopherol tissue levels on beef quality. Animal, 5, 2010-2018.

Peisker, C. (1989) Phytol and breakdown of chlorophyll in senescent leaves. J. Plant Physiol., 135, 428-432.

Rise, M. et al. (1988) Accumulation of $\alpha$-tocopherol in senescing organs as related to chlorophyll degradation. Plant Physiol., 89, 1028-1030.

Sabater, B. \& Rodriguez, T. (1978) Control of chlorophyll degradation in detached leaves and oat through effect of kinetin on chloropyllase levels. Physiol. Plant., 43, 274-276.

Saigusa, T. et al. (2006) Temporal changes in vitamin E content in forage rice cultivars. Nihon Souchi Gakkaishi (Jap. J. 
Grassl Sci.), 52 (Supl. 1), 130-131 [In Japanese].

Sato, S. et al. (2014) Forage potential of barley (Hordeum vulgare L.) genotypes for an annual crop rotation combined with forage rice (Oryza sativa L.) in the North Kantoh Area. Nihon Souchi Gakkaishi (Jpn. J. Grassl. Sci.), 60, 77-84 [In Japanese with English summary].

Serbinova, E. et al. (1991) Free radical recycling and intramembrane mobility in the antioxidant properties of alpha-tocopherol and alpha-tocotrienol. Free Radical Biol. Med., 10, 263-275.

Sookwong, P. et al. (2007) Quantitation of tocotrienol and tocopherol in various rice brans. Journal of Agricultural and Food Chemistry, 55, 461-466.

Tuyuzaki, H. \& Kawashima, C. (1993) Growth and Senescence in wheat organs. II. Change in dry weight, nitrogen and chlorophyll content of differently positioned leaf blades and sheaths on a stem. Nihon Sakumotsu Gakkai Kiji (Jpn. J. Crop Sci.), 62 (suppl.), 182-183 [In Japanese].

Yamada, T. et al. (2012) Effect of fermented TMR containing whole crop rice silage on carcass traits and lipid stability of meat in Japanese Black steers. Nikuyougyu kenkyuukaiho (Bulletin of Beef Cattle Science), 92, 4-9 [In Japanese with English summary].

Yamazaki K. et al. (1997) Studies on functional components of malting barley. Tochigiken syokuhinkougyo Shidosho Kenkyu Houkoku (Report of the Institute for Food Technology Tochigi Prefecture), 11, 5-7 [In Japanese]. 